\title{
Recursos mediáticos en la práctica educativa de E/LE en la Universidad de Relaciones Internacionales de Moscú (MGIMO)
}

\author{
VICTORIA YAKOVLEVA \\ Universidad de Relaciones Internacionales de Moscú (MGIMO) \\ YULIA VERESHCHINSKAYA \\ Universidad de Relaciones Internacionales de Moscú (MGIMO) \\ international@inno.mgimo.ru
}

\begin{abstract}
Resumen: Este trabajo está dedicado a compartir la experiencia de la práctica didáctica del uso de los recursos mediáticos en clase de E/LE. Analizamos la eficacia de tipos de materiales audiovisuales en la aplicación al proceso educativo tanto en el marco del curso general de los niveles A1-A2, B1-B2, como en el marco del español con fines específicos (B2-C1). En este trabajo exponemos las técnicas utilizadas en la MGIMO con apoyo de recursos mediáticos como uno de los mejores métodos para transmitir la lengua en un contexto real, explorando sus peculiaridades lingüísticas y extralingüísticas.
\end{abstract}

Palabras clave: texto mediático, recursos audiovisuales, medios de comunicación, Español con Fines Específicos, competencias auditivas.

Abstract: This work is dedicated to share our educative practice experience in the use of media resources in the SFL. We analyze the efficiency of types of audiovisual materials in their didactic and pedagogical implications in the general course A1-A2, B1-B2 as well as in the course of Spanish For Specific Purposes (B2-C1). We expose the methodology of application of such instruments at the MGIMO University as one of the best methods to transmit the language in the real context with exploring of its linguistic and extra linguistic peculiarities.

Key words: mediatext, audiovisual resources, mass media, Spanish For Specific Purposes, listening skills. 


\section{Introducción: sobre la importancia de los recursos mediáticos.}

Los recursos mediáticos para los efectos de nuestra comunicación son los recursos que poseen tanto características verbales como de medios de comunicación, o sea se trata del estudio didáctico del uso del texto mediático (Vereshchinskaya, 2013: 30) que puede ser escrito u oral; tiene diferentes canales de distribución: prensa escrita, radio, televisión, Internet; abarca un gran panorama de temas, por ejemplo: política, negocio, deporte, cultura, tiempo y otros que reflejan las peculiaridades nacionales, culturales y lingüísticas de los discursos de una u otra comunidad lingüística; asimismo se emplea en la enseñanza de E/LE en la MGIMO según el nivel y fines específicos de los estudiantes. En uno de los capítulos del Marco Común Europeo de Referencia para las Lenguas podemos leer: «Todas las competencias humanas contribuyen de una forma $\mathrm{u}$ otra a la capacidad comunicativa del usuario y se pueden considerar como aspectos de la competencia comunicativa» (2002). Con este objetivo nosotros, los profesores, tenemos que apoyarnos en el enfoque orientado a la acción, propiciando situaciones en las que los alumnos tengan que hacer uso de la misma, para lo cual es necesario el desarrollo de las destrezas lingüísticas, sobre todo comunicativas.

El Marco Común Europeo de Referencia para las Lenguas en su capítulo 4, analizando las actividades comunicativas de la lengua, dice que "para llevar a cabo tareas comunicativas, los usuarios tienen que realizar actividades de lengua de carácter comunicativo y poner en funcionamiento estrategias de comunicación» (2002). Este documento especifica una lista de las destrezas que elaboramos en nuestras clases y las clasifica en actividades comunicativas de compresión, de expresión, de interacción y de mediación, cada una subdividida según sea el canal oral o escrito:

La comunicación y el aprendizaje suponen la realización de tareas que no son sólo de carácter lingüístico, aunque conlleven actividades de lengua y requieran de la competencia comunicativa del individuo; en la medida en que estas tareas no sean ni rutinarias ni automáticas, requieren del uso de estrategias en la comunicación y en el aprendizaje. Mientras la realización de estas tareas suponga llevar a cabo actividades de lengua, necesitan el desarrollo (mediante la compresión, la expresión, la interacción o la mediación) de textos orales o escritos.

Consejo de Europa (2002)

En el mundo contemporáneo, cuando va creciendo la importancia del espacio informativo, los medios de comunicación adquieren nuevas formas y crean sus propias peculiaridades de percepción de información y cambios lingüísticos actuales que se tienen en cuenta a la hora de impartir clases de lengua. Además, la mayor parte de lo que saben nuestros estudiantes sobre el mundo actual lo han sacado del cine y la televisión. La comunicación masiva se considera en nuestra ponencia, no solo el proceso de distribución de información, sino también el sistema de organización de mensajes. Los medios de información, siendo recién emitidos, reflejan de la mejor manera el español actual, su uso, sus cambios gramaticales, léxicos, sintagmáticos, etc.

\section{Texto mediático como recurso didáctico.}

En nuestra actividad profesional los profesores de E/LE de la Universidad MGIMO recurrimos a los materiales visuales, auditivos y audiovisuales que por una parte facilitan el aprendizaje y la comprensión de la materia, y por otra parte son fuente del 
conocimiento lingüístico y extralingüístico. Hay que tener bien entendido que la eficacia del uso de diferentes materiales ilustrativos está principalmente en correlación con las explicaciones verbales y la presentación del material visual o audiovisual, de la destreza del profesor que se vale de las particularidades y regularidades que revelan la esencia del tema estudiado.

\subsection{Contenido didáctico del material audiovisual.}

Aunque el trabajo con los materiales audiovisuales puede representar ciertos problemas, técnicos en su mayoría, sus peculiaridades son incomparables, ya que la presentación de un vídeo facilita la posibilidad de operar varios contenidos simultáneamente: socioculturales, lingüísticos, extralingüísticos, gramaticales, variedades del español, etc.

De estos materiales audiovisuales los estudiantes conocen unidades léxicas nuevas, entienden con más facilidad una regla gramatical en su funcionamiento, el significado de una palabra en su uso en un contexto dado, se transmiten contenidos culturales de forma más directa, se consigue una comunicación improvisada en el aula. Las imágenes son un estímulo visual que provocan sensaciones y recuerdos, aportan información, constituyen consejos o advertencias. Se observa la combinación de la comprensión auditiva, visual y destrezas comunicativas e interpretativas en el proceso de aprendizaje.

La elección de una imagen visual o audiovisual dependerá antes que nada de su finalidad, si la vamos a usar para introducir un tema, un nuevo campo semántico, una noción cultural, etc. Además, aprendiendo con el material audiovisual los estudiantes se hacen protagonistas de su aprendizaje. Trabajar con los materiales que le dan variedad a la clase genera más motivación y acción ya que el profesor deja de interpretar su papel tradicional de profesor-expositor; los estudiantes afrontan un nuevo desafío: combinar la comprensión auditiva y visual a la hora de comentar la nueva información obtenida; la interacción entre el profesor y los alumnos mejora porque la reacción es más viva e inmediata; los estudiantes tienen posibilidad de trabajar en equipo, grupos, parejas, individualmente.

\section{Especificidad del proceso de enseñanza en la MGIMO.}

La especificidad de la enseñanza en la MGIMO consiste en la misma orientación de relaciones internacionales de todas las facultades con las que cuenta la Universidad: Facultad de Relaciones Internacionales, de Derecho Internacional, de Relaciones Económicas Internacionales, de Periodismo Internacional, de Gestión Pública, de Ciencias Empresariales y de Ciencias Políticas.

El español se imparte en la Universidad MGIMO como primera lengua (10 horas lectivas a la semana) y segunda lengua (6 horas lectivas a la semana) y corresponde a los niveles del A1 al C1 (Máster). A partir del tercer año la enseñanza de la primera lengua ya es diversificada pues se introducen clases de orientación profesional: traducción (jurídica, económica o política según la facultad) y Español con Fines Específicos; es decir se exploran y se practican las destrezas y habilidades profesionales. Al mismo tiempo en el tercer año en todas las facultades, sin perjuicio de la orientación profesional, se imparten clases del lenguaje mediático, es decir el lenguaje político de la prensa escrita y de los telediarios. Español con Fines Específicos 
adquiere esta posibilidad de ser introducido en el proceso educativo a partir del segundo trimestre del segundo año.

\subsection{Materiales audiovisuales en la clase de E/LE en la MGIMO.}

A cada nivel y fin específico les corresponde su propio material mediático. En las clases de E/LE utilizamos los siguientes tipos de materiales audiovisuales:

- Cortometrajes

- Audiolibros

- Documentales

- Programas de TV y telediarios,

- Internet: páginas web de los periódicos, revistas digitales profesionales, blogs, entrevistas de profesionales en directo o grabadas, todo tipo de vídeos o información de referencia que pueda surgir durante la clase.

\subsection{Temporalización.}

La duración del vídeo necesario depende de los fines didácticos y el nivel de los aprendientes. Por ejemplo, los estudiantes del A1 escuchan diálogos y textos de 1-2 minutos; los del A2, 3-4 minutos, ven películas educativas durante 5-10 minutos; los alumnos del nivel B1 ven cortometrajes, documentales de duración de 10-15 minutos, escuchan diálogos como conversaciones por teléfono de mayor complejidad de 2 o 3 minutos; en el nivel B2 se introducen los telediarios como un elemento imprescindible de la práctica educativa de E/LE en la MGIMO, una noticia no debe durar más de 2 minutos; los estudiantes del $\mathrm{C} 1$ son capaces de comprender e interpretar una noticia o una entrevista de 3 o 4 minutos. Estos tipos de películas o vídeos no duran mucho, lo que facilita que la proyección no sea el centro de la clase, sino que la clase gire alrededor de los temas expuestos en la película o en el telediario. Además, representan una estructura que tiene elementos básicos y sobre los cuales los estudiantes pueden organizar sus actividades. En consecuencia, las representaciones filmicas dan cuenta de un espacio y un tiempo, de unos personajes y de unos rasgos propios de la cultura que exponen.

Todos los grupos de la primera lengua tienen una clase audiovisual a la semana aparte de otras clases de español. Según el nivel de los aprendientes, los métodos, materiales y evaluación de los estudiantes son diferentes.

\subsection{Niveles A1 - A2.}

Los estudiantes de primer año que acaban de empezar a aprender el idioma en estas clases escuchan diálogos y textos y ven vídeos del nivel correspondiente con repetidas representaciones. Una clase contiene tales actividades de la lengua, así como comprensión auditiva, expresión oral y escrita e interacción oral. Se forman y se desarrollan las siguientes destrezas y competencias lingüísticas: fonéticas (pronunciación y entonación) y léxico-gramaticales. De esta manera se agilizan tanto las competencias generales como las competencias comunicativas. En la clase el profesor 
trata de conseguir que la reacción sea más viva e inmediata. Además, los estudiantes tienen posibilidad de trabajar en equipo, grupos, parejas, individualmente, dramatizando e interpretando los diálogos escuchados.

\subsubsection{Películas en la clase de E/LE de A1 - A2.}

Una de las mejores herramientas para combinar dichas actividades es el cine, que ayuda al alumno a comprender el aspecto cultural en el que se enmarca la película como, por ejemplo, las costumbres, situación histórica, política y social, expresiones propias de la región, entre otras.

En el nivel A1-A2 para estos fines sirven las películas didácticas. Una de ellas es la película "Español extra", filmada por la compañía televisiva inglesa Channel $4 \mathrm{y}$ elaborada didácticamente por las profesoras de la MGIMO V. Yakovleva y E.Syshchicova (2015), que contiene 14 episodios cómicos y abarca materiales didácticos para los niveles A1-A2, incluyendo situaciones de la vida cotidiana de los jóvenes:

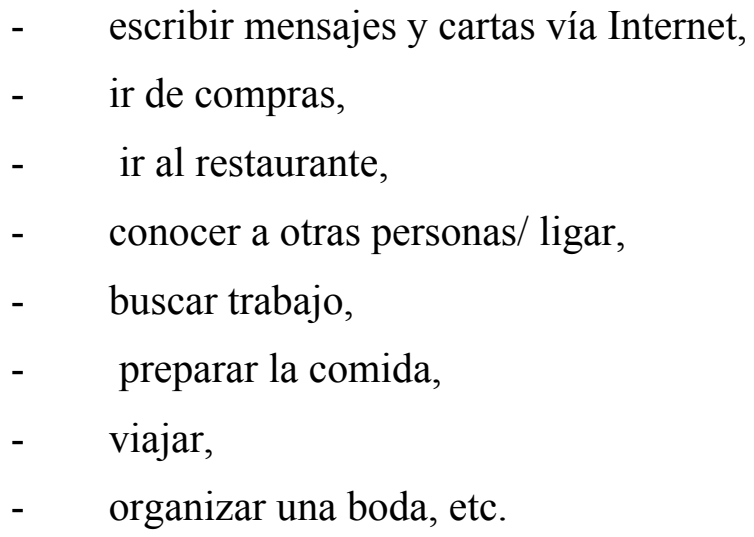

Antes de visualizar cada episodio les damos a los alumnos el comentario del léxico nuevo, que aparecerá en el episodio. Después de ver el episodio los aprendientes hacen un test para comprobar la comprensión. El test contiene 5 puntos y 3 variantes de respuestas, entre las cuales los alumnos elegirán la correcta. Luego se presenta la segunda visualización y las preguntas para desarrollar el contenido y practicar la gramática. Entre las actividades de postvisualizasión están los juegos léxicos (sopa de letras o crucigramas, dar definiciones de algunas palabras), imitación, interacción y mediación, y algo de teatro: componer diálogos entre los personajes, representar su papel correspondiente y otras. Las actividades para la expresión escrita son redactar una carta de un personaje a otro, dar su opinión en cuanto a uno de los temas ofrecidos. Como nuestro sistema de aprendizaje de lenguas extranjeras supone la traducción, entre las actividades escritas se observan ejercicios de traducción del ruso al español, que deben hacer los alumnos utilizando el léxico nuevo de la película.

\subsection{Nivel B1.}

Los estudiantes del segundo año también tienen una clase a la semana combinada: una parte de la clase se dedica a la audición de diálogos y textos más complicados de situaciones concretas de diferentes ámbitos (el viaje, el ocio, las conversaciones 
telefónicas, el trabajo, las relaciones personales, etc.) para practicar destrezas de la comprensión auditiva y expresión oral. Se hacen simulaciones de estas situaciones, se expresa la opinión o presentaciones relacionadas con algún tema estudiado. En otra de las partes se visualiza un cortometraje o un documental y realiza el desarrollo de un trabajo práctico no solo con las destrezas auditivas y comunicativas, sino también con los hábitos creativos de los estudiantes (pensar, reflexionar, razonar).

\subsubsection{Cortos en la clase de E/LE del B1.}

A continuación, se ofrece una propuesta breve para trabajar con el cortometraje.

El corto argentino "Sueños" (2010), de una duración de 10 minutos, nos presenta además de una historia muy interesante y extraordinaria, las realidades lingüísticas y extralingüísticas argentinas.

Todas las tareas se dividen en tres partes: preaudiovisual, audiovisual y postaudiovisual. La tarea preaudiovisual consiste en:

- analizar el título de la película,

- dar equivalentes a las palabras argentinas (por ejemplo: colectivo, bondi, bancar, che, etc.) y explicaciones de la gramática (por ejemplo, el uso del voseo),

- explicar en español los vocablos clave para el entendimiento del argumento (por ejemplo: sueño, anhelo, publicidad, apuro).

Tras ejercer este tipo de actividades proseguimos a la tarea audiovisual: se visualiza el corto $(2 \mathrm{~min})$ donde el protagonista hace la publicidad de un producto de uso diario, se analiza el lenguaje de la publicidad (amable atención, de extrema calidad, súper importante, un set increíble, de un acero indestructible) y métodos de atraer a los compradores posibles (manera de oferta), se propone a los aprendientes que hagan la publicidad ellos mismos. Una vez terminadas las presentaciones publicitarias sigue la visualización de la película, después de la cual vienen las preguntas del profesor dirigidas a trabajar las destrezas de expresión argumentativa oral.

La tarea postaudiovisual puede consistir en:

- hacer la sinopsis del cortometraje,

- dar sus comentarios,

- contar alguna historia de su vida o leyenda relacionada con el argumento de la película,

- escribir el ensayo sobre el tema: "Creer que todo es posible” o “Cómo hacer realidad un sueño ajeno/suyo?"

\subsection{Nivel B2.}

El tercer año de aprendizaje en la MGIMO es crucial, ya que se exploran materiales mediáticos de un nivel completamente distinto: telediarios, periódicos digitales $\mathrm{o}$ impresos, videoblogs de temas profesionales, entre otros. 


\subsubsection{Telediario como recurso didáctico.}

El trabajo con el telediario está orientado, en primer lugar, a la comprensión auditiva. Pero a la vez se extraen vocablos desconocidos. El papel del profesor también se diferencia en esta etapa: lo principal en el trabajo con el léxico es ofrecer diferentes situaciones, donde se usan los vocablos extraídos, buscar palabras del mismo significado y antónimos si es posible, formar o componer un vocabulario temático a base del episodio visto. Por ejemplo, en el noticiero se trata de la visita del Ministro de Asuntos Exteriores al país extranjero. De ahí podemos completar la lista de expresiones referentes al tema: visita oficial / extraoficial; visita de trabajo, visita de amistad / de cortesia; efectuar / realizar / hacer una visita; arribar / llegar a algún lugar en visita; encontrarse / estar / permanecer de visita. Además, los alumnos comentan lo que conocen del tema, bien político, bien profesional, en función del vídeo explorado.

Los medios de la comunicación masiva no dejan de influir en las personas, modificando sus opciones, sus costumbres, su modo de ver y su opinión. La prensa nos permite mantenernos en continua comunicación con distintos sucesos sociales, políticos y económicos tanto a escala nacional como internacional. Por eso el periódico, la televisión e Internet son una fuente importante para permanecer informados de la mayoría de los acontecimientos, analizar la situación política, económica, sociocultural y otras, asimismo estudiar los métodos de manipulación de los lectores/espectadores, los aspectos léxico-gramaticales actuales del idioma.

\subsubsection{Periódoco como recurso didáctico.}

En el marco del trabajo con los textos periodísticos, una de las tareas más importantes para nuestros estudiantes es saber hacer el resumen analítico del artículo publicado en Internet o prensa escrita, lo que prevé realizar diversas destrezas y competencias comunicativas: determinar el tema principal del texto; trazar los problemas que abarca el autor, exponerlos basándose en el texto del artículo; presentar argumentativamente las conclusiones a las que llega el periodista y su opinión; dar sus comentarios respecto a la idea del texto.

\subsection{Niveles B2 - C1.}

\subsubsection{Español con Fines Específicos en la MGIMO.}

El cuarto año se caracteriza por su orientación profesional: seis horas lectivas de las diez a la semana están dedicadas al Español con Fines Específicos. A diferencia del tercer año, cuando en las clases de traducción se exploran y se traducen los documentos básicos profesionales (la Constitución y los códigos civil, penal, administrativo, Ley de Trabajadores, la Carta de la ONU, entre otros), en el cuarto se trabajan destrezas de traducción de documentos actualizados: tipos de contratos, correspondencia comercial, notas diplomáticas, etc. A este efecto recurrimos a los comentarios actualizados de los profesionales en cada ámbito, a programas consultativos interactivos, a telediarios, entrevistas y discursos grabados o en directo de los líderes políticos, procesos abiertos, sesiones del Consejo de Seguridad de la ONU. Estos recursos mediáticos ya están 
orientados a la audición y comprensión auditiva, ya no se interpretan los materiales visualizados o escuchados.

El núcleo de estas clases es análisis y comentario de lo visto/escuchado desde el punto de vista profesional, elaboración colectiva de una estrategia para actuar luego en una simulación de un proceso judicial, o sesión del Consejo de Seguridad o en una simulación llamada Modelo de la ONU, cuando los estudiantes actúan en calidad de jueces, fiscales, abogados, miembros del Consejo de Seguridad, diplomáticos y representantes permanentes. Ya en el Máster los alumnos pueden dar consejos profesionales en un blog o participar en un foro profesional, al igual que formalizar un contrato, mantener correspondencia con una empresa, donde se llevan a cabo las competencias de expresión escrita.

\subsubsection{Texto mediático en la clase de E/LE del B2 - C1.}

Lo que se refiere a los tipos de trabajo con el texto, se destacan varios: traducción del español al ruso y del ruso al español, traducción hecha sin preparación previa y resumen analítico de un texto extraído de un periódico digital o una revista profesionalmente orientada, especificando el problema principal, temas vinculados, la actitud del autor hacia la problemática del texto mismo y dando su comentario profesional en cuanto al tema.

Además de las actividades realizadas en clase el estudiante debe trabajar con los medios de comunicación fuera del aula para mejorar la calidad de su comprensión auditiva escuchando la radio, viendo la tele o teniendo contacto directo con diferentes registros del español.

\section{Conclusiones.}

La experiencia práctica expuesta en esta comunicación sirve para mostrar las técnicas y la metodología que utilizamos los profesores de la Universidad en nuestras aulas. El uso de los recursos mediáticos en la clase de E/LE supone una oportunidad excelente para presentar situaciones reales de lengua, lo que lo convierte en un método ideal para transmitir la lengua en un contexto sociocultural real. Usamos las nuevas tecnologías para dar a nuestras clases mayor interés y alcanzar una participación activa de los alumnos.

La distribución del material mediático didáctico según los niveles de los aprendientes contribuye a la mejor organización del proceso educativo y hace que los alumnos aprendan y usen la lengua de una manera adecuada. Los recursos mediáticos sirven de soporte a los manuales de gramática y otros materiales tradicionales, ya que de este modo el proceso de aprendizaje llega a ser más activo, interactivo, o sea más vivo.

\section{Bibliografía:}

CARracedo Manzanera, C. (2009). Diez ideas para aplicar el cine en el aula. Recuperado el 17/06/2016, de:

http://cvc.cervantes.es/ensenanza/biblioteca_ele/publicaciones_centros/pdf/manila_2009 /16_aplicaciones_03.pdf 
Edinson Almeida Calderón, J., Yiseth Fuentes Bayona, A. (2011). «El uso de materiales audiovisuales en la clase de Español como Lengua Extranjera: Implementación de una propuesta didáctica». Docencia Universitaria, 12, 81-132.

GENI, A. (2015). Más allá de la competencia comunicativa. Recuperado el 21/06/2016, de: $\mathrm{http} / /$ formacionele.com.

IAKOVLEVA, V. y SAVTCHUK, E. (2015). «El soporte audiovisual en clase de ELE: el uso de las películas». Cuadernos iberoamericanos, 2 (8), 103-108.

IAKOVleva, V. y Syshchicova, E. (2015). Ispanskiy s udovolstviem. Espñol extra. Niveles A1-B1. Moscú: MGIMO.

Consejo de Europa (2002). Marco Común Europeo de Referencia para las Lenguas. Recuperado el 14/06/2016, de: http://cvc.cervantes.es/.

VERESHCHINSKAYA, Y. (2013). «Ispanskiy gazetny zagolovok: lingvopragmatichesky y nazionalno-culturny aspecty (Titulares de artículos periodísticos: aspectos liguapragmático, nacional y cultural)». Tesis doctoral, Universidad de Moscú: Moscú. 